\title{
Feedback as a mechanism for improving students' scientific communication skills
}

\author{
Daryl McPadden, ${ }^{1}$ Patti C. Hamerski, ${ }^{1}$ Marcos D. Caballero, ${ }^{1,2,3}$ and Paul W. Irving ${ }^{1}$ \\ ${ }^{1}$ Department of Physics and Astronomy, Michigan State University, East Lansing, Michigan 48824 \\ ${ }^{2}$ CREATE for STEM Institute, Michigan State University, East Lansing, Michigan 48824 \\ ${ }^{3}$ Department of Physics \& Center for Computing in Science Education, University of Oslo, N-0316 Oslo, Norway
}

\begin{abstract}
Communication is cited as an important scientific skill in institutional standards such as the Next Generation Science Standards and the American Association Physics Teachers laboratory guidelines; however, there are few suggestions on how to support students in developing these communication skills in science. As a possible mechanism for helping students improve their communication skills, we present a scaffolded feedback system, which has been built into the reformed, introductory E\&M course. At the beginning of the semester, students receive feedback from an instructor each week about their individual understanding, their group collaboration, and their problem solving process in class. By the end of the semester, students are asked to reflect and write this feedback for themselves. From a case study, we demonstrate the impact of the weekly feedback system on changing and improving a student's communication in this course.
\end{abstract}

\section{INTRODUCTION AND BACKGROUND}

Scientific communication is an important skill for developing expertise in a STEM discipline, which includes both formal and informal communication. In recent scientific guidelines, communication has been listed as a critical practice across disciplines and levels [1-4]. For example, the American Association of Physics Teachers (AAPT) laboratory guidelines have listed "Communicating Physics" in "appropriate and authentic written and verbal forms" as one of six focus areas for the undergraduate physics lab curriculum with listed standards for both the introductory and advanced levels [1]. Additionally, the Next Generation Science Standards (NGSS) have listed "Obtaining, Evaluating, and Communicating Information" as one of the eight Scientific and Engineering Practices to be developed through K-12 science courses, stating that "Scientists and engineers must be able to communicate clearly and persuasively the ideas and methods they generate. Critiquing and communicating ideas individually and in groups is a critical professional activity" [2].

While the standards such as those listed in the NGSS practices and the AAPT laboratory guidelines highlight the critical importance of scientific communication and suggest that our science courses should be improving in part students' communication skills, they do not provide recommendations or strategies for how to help students develop these skills $[1,2]$. For instance, one of the NGSS standards says that students should be able to "communicate scientific and/or technical information or ideas...in multiple formats (including orally, graphically, textually, and mathematically);" however, NGSS does not list suggestions for how to help students improve their oral communication skills or how those suggestions might be different from helping students develop their written (or textual) communication skills [2].

Similarly, the AAPT laboratory guidelines for both introductory and advanced levels suggest that "Students should be able to effectively plan and carry out experiments and discuss ideas in small groups as part of the overall scientific process" [1]. Yet, simply providing opportunities for students to "discuss ideas in small groups" does not necessarily mean that students are improving in their ability to communicate their ideas with their peers or instructors, especially considering that physics can have a negative reputation with regards to who is allowed to be an "expert," who is allowed to ask questions, and who is allowed to disagree. Despite the importance the curriculum guidelines place on scientific communication, the guidelines lack a description of supportive mechanisms for helping students develop these skills over the time span of a course.

Recently in physics education research, there has been a push to develop curricula that address the standards put forth in these guidelines, which are explicitly focused on developing these scientific skills in addition to content knowledge $[2,4]$. As part of these reformed classrooms and curricula, there have been some mechanisms proposed for improving students' formal communication skills. For example, the Investigative Sciences Learning Environment (ISLE) courses have a set of rubrics designed for assessing scientific abilities in weekly written laboratory reports, one of which is explicitly aimed at assessing a student's ability to communicate scientific ideas $[5,6]$. The rubrics provide students with clear expectations of what should be included in their report and a detailed description of what the criteria are for each score (including Adequate, Needs Improvement, Inadequate, or Missing categories). Students can use the rubrics and their scores to improve the quality of their technical writing and scientific communication over the semester [6]. However, this system is limited in that it only applies to the written forms of communication that are worked on and turned in outside of class.

Other curricula have moved beyond weekly laboratory reports to include an oral poster presentation at the end of the semester [7, 8]. The poster presentation serves in place of a final examination and allows students the opportunity to present their work to their peers and instructors in a scientifically-authentic way. While these poster presentations allow for the evaluation of students' oral communication skills, they are limited in that they occur only once or twice a semester, which hinders the amount that students can improve. Additionally, the poster presentations are inherently a formal presentation of the work students have already completed. Even combined with an assessment of students' written communication skills, there is still little done to help students improve their communication in small group discussions or during the in-class laboratories/activities. As high- 
lighted by the NGSS and AAPT guidelines, scientific communication includes participation in informal discussions (in addition to formal presentations) [1,2], which has become a more prominent feature of introductory physics curricula particularly in studio- and flipped-style courses.

Given that informal communication has a growing role in introductory physics and is highlighted as an important scientific practice, we use this paper to describe a feedback mechanism that was built into the Electricity and Magnetism Projects and Practices in Physics (EMP-Cubed) course, which was designed in part to help students improve their verbal communication in class. We then present a case study of how a student, who we will call Elsie, interacted with and was impacted by the feedback over the semester.

\section{FEEDBACK SYSTEM AND COURSE CONTEXT}

EMP-Cubed is a calculus-based, introductory electricity and magnetism physics course that was designed at Michigan State University. EMP-Cubed was developed in the last year as the second course in the introductory sequence following the introductory mechanics course - Projects and Practices in Physics (P-Cubed) [9]. Both P-Cubed and EMP-Cubed are flipped, project-based courses that integrate minimallyworking computational projects into the course. Every week, students read a set of notes prior to class and complete a conceptual-based homework assignment over those readings. During class, which meets twice a week for 2 hours, students work in groups of 4-5 to complete a complex, real-world project that requires them to set goals, create a solution plan, make simplifying assumptions/approximations, and evaluate their solution. Following class at the end of the week, students complete a calculation-based homework assignment, which applies the ideas that they had been using and developing over the course of the week.

As a part of the P-Cubed and EMP-Cubed courses, students also receive written feedback every week that contains two sections - one that is specific to each individual student and one that addresses the group as a whole. For the scope of this paper, we will focus on the individual feedback. In EMP-Cubed, the individual feedback is structured around three categories: Individual Understanding, Process Skills, and Group Collaboration. Individual Understanding highlights how well the individual student understood the material for the week; Process Skills highlights how the student contributed to the group's planning, modeling, and decision making; and Group Collaboration highlights how the individual student contributed to the functionality of the group and their peers' understanding of the project. Each paragraph of feedback then outlines: 1 ) something that the student did well that week (within their strongest category), 2) something that the student should work on for the following week in their weakest category, and 3) a strategy that would help them improve [9].

In P-Cubed, the individual feedback is entirely provided by the tutors in the course, which include physics faculty, graduate teaching assistants (TAs), and undergraduate learning assistants (LAs). (Since the faculty, TAs, and LAs function in the same manner in class, we refer to them all as "tutors.")
In the class, there are approximately 8 students to one tutor, so the tutor is able to pay attention to how each student functions in the group and provide personalized feedback for each student. In contrast, in EMP-Cubed, the individual feedback is slowly transitioned from being written entirely by the tutors to being written entirely by the students. This system is set up to help scaffold a progression from tutor-driven feedback to self-reflective feedback from the student. For the first five weeks of the course, the individual feedback is entirely written by the tutors (just like in P-Cubed). In the subsequent three weeks, students are asked to provide their own feedback for the Group Collaboration category, while the tutor provides feedback on the other two categories of individual feedback (and the group feedback). In the final eight weeks of the course, students are asked to reflect on all three categories for the individual feedback (while the tutor provides the group feedback for the week and reviews students' selffeedback).

As a teaching tool, this weekly feedback system provides a mechanism to help students develop their scientific skills, including their informal, verbal communication in class that would not otherwise be observed or evaluated. Since the feedback happens every week, it provides the opportunity to help students progress and build on their skills through the semester. In addition, the feedback progression in EMPCubed is designed to help students develop reflective practices and provide better feedback for themselves.

From this feedback system, we see students change how they interact in class and improve their scientific skills. In the subsequent sections, we show a case study of a student, Elsie (pseudonym), which demonstrates how the weekly feedback impacted her scientific communication both in the EMP-Cubed class and in her other course work. We present data selected from an interview with Elsie, from her written tutor feedback, and her written self-feedback.

\section{CASE STUDY: ELSIE}

At the end of the EMP-Cubed course in Fall 2017, we conducted interviews with students to study the development of the course and the scaffolded feedback system outlined above. We developed a semi-structured interview protocol that focused on three main topics: students' impressions of the course and course structures, how they interacted with the feedback system in the course, and what students thought they would take away from the course. After the initial protocol development, we edited and removed questions for length. Three students were recruited from the EMP-Cubed course by an in-person announcement at the beginning of class in the 11 th week of the semester (out of 15 total weeks). The interviews were then conducted in the 13th week of the semester by the third author (who was not an instructor in the course) and were approximately an hour long. Students were compensated with a \$10 Amazon gift card for their participation.

From this set of interviews, we focus on Elsie - a sophomore, engineering student in EMP-Cubed during the Fall 2017 semester. Introductory electricity and magnetism was required for her major; however, she picked the EMP-Cubed section of introductory electricity and magnetism because she 
enjoyed small group work in high school and was drawn to the project-based nature of the course. Elsie did not take PCubed for her introductory mechanics course requirement, so the EMP-Cubed course was her first exposure to the classroom structures and feedback mechanism. Below we present the segments from the interview in which Elsie discusses the impact that the feedback had her. In particular, we selected the quotes where she discusses how feedback impacted her ability to voice her opinion to the group, which is language that she repeated several times in the interview. We then related what Elsie said in the interview to excerpts from the written feedback she received from the tutor or her selffeedback. For the following quotes, the bolded emphasis was added by the authors.

When Elsie was asked how feedback was going for her and what kind of feedback she was getting, she responded:

\section{I really enjoyed the [feedback] emails. I get excited every Tuesday morning [laughs] to like read it. I think every...it's always something good and some- thing that...it's either something that I didn't notice be- fore or that I was thinking too but was kind of on the back burner. So one of the things that was like really early on that [the tutor] suggested me doing was voic- ing my opinion more and not...not holding it in or not... or questioning myself when I was unsure. And I didn't really notice myself doing that until I started actually just saying it...if I thought of something then I'd say it out loud. I wouldn't question myself. And that has been super beneficial in like all aspects of life [laughs], not just like this class...yeah or, I dunno, in all of my courses. \\ - Elsie Interview Week 13 (22:32)}

In this quote, Elsie is referring to the feedback that she received after the second week of class from her tutor. During class that week, Elsie and her group had completed two projects, one of which involved calculating the electric field from a charged thundercloud and the other creating a computational model of the electric field from that cloud. Elsie's tutor had told her:

This week I was glad to see more shared control of the markers and that you were taking control of the computer on the coding day. I also appreciated how you wrote out what the electric field would be by hand first. This sort of analytic prediction can not only help you write the code in the computer but also check whether it is right. One thing I would like to see you work on next week is being able to voice when you disagree or when something is confusing you. For example, when the group started talking about electric potential as vector on Tuesday, I could tell that you did not agree with that idea (and you were right - electric potential is a scalar) but you weren't confident in saying it. It's perfectly ok to disagree with the group and ask questions - this will help not only your own understanding but also your group's.

- Elsie's Tutor Feedback Week 2

This feedback that Elsie received in the second week of the course changed how Elsie was communicating with her group members in EMP-Cubed. By explicitly telling Elsie that is was okay to ask questions and voice your opinion even when you are not $100 \%$ confident, her tutor was able to help Elsie change how she participated in class, which would not have been possible with traditional forms of assessment like exams, written reports/homework or final presentations.

When she starts to write her own feedback, Elsie begins to take up this practice of voicing her opinion, particularly reflecting on and trying to improve this skill. In the first feedback that she writes for herself (during Week 6), she writes:

I think that I can improve taking charge of the computer a little bit more on coding day and voicing my ideas on how to write the code. Since I am such an amateur coder, I do not tend to be the most confident voicing my ideas, but on Tuesday I did not voice them even though the end result was very similar to my original thoughts. If I had voiced my opinions, we might have been able to save a good 5 minutes of confusion. -Elsie's Self Feedback Week 6

Elsie states that she particularly wants to improve on voicing her questions and ideas in one area (coding) that she is not particularly confident in her skills. She is recognizing that she could have contributed to the group solution and saved confusion if she had shared her ideas with the group earlier. In the following week, she shares her reflections on what happened in class when she tried to voice her ideas more:

This week I tried really hard to voice my doubts and confusion and question the other members of the group more. I think that this was very effective in keeping us all on the same page and working as a group as my questions/doubts/confusion were usually shared by others as well. -Elsie's Self Feedback Week 7

From her feedback, we see that Elsie made attempts to change how she interacted with and communicated with her group members in class. She highlights that this was beneficial to keeping the group together during the problem and that she typically was not the only one who had that question. Thus, we see that Elsie has built onto the feedback that her tutor gave her in Week 2 and is seeing benefits in her group work when she specifically tried to improve on this skill. From her interview, Elsie states that this improvement in her communication skills has been advantageous, not only for the EMP-Cubed course, but also in her other course work. For example, she says that she is more willing to ask questions in her Engineering 102 course, which is the Introduction to Engineering Modeling course at MSU. Elsie explains:

Yeah, I guess just like questioning things. I've ended up...probably for Engineering 102, I don't know if I would have done it as much, but if I don't understand something, then I will email the TA right away. Or try to figure it out, but then email the TA, and just kind of get their input and everything. That helps so much and really helps my frustration level as well and time constraints. So I think that would be one of the best examples of me being able to translate it to another class. Just yeah...realize that voicing is important and 


\section{not just to hold it in.}

- Elsie Interview Week 13 (24:43)

Elsie describes how she has taken this practice of voicing her opinion and asking questions when she does not understand something to a completely different course, which has benefited her particularly in managing her time and frustration. Thus, we see that the feedback mechanism is not only helping Elsie communicate in the EMP-Cubed course but that improving this skill has had positive impacts in her other courses as well. She even says later in the interview that this is a skill that she will bring up in job interviews when asked about what she is trying improve:

I've talked about in interviews and everything...like job interviews... as a skill that I'm trying to improve or something is definitely verbalizing everything. If I don't feel comfortable, even if I don't feel 100 percent confident in my ideas or whatever, I'll say it anyway. And I notice that about myself, I tend to be a pretty confident person until it comes to things that I'm not 100 percent on. And so, that's definitely been helping...or I've seen that be a good thing to do.

- Elsie Interview Week 13 (48:10)

From this quote, Elsie shows that she views this communication skill as something that she is still working on, but that she has already seen some of its benefits, including improving her group work, reducing frustration, managing time constraints, and feeling like she is not alone in having questions or doubts. These quotes also demonstrate that Elsie sees this aspect of communication as not only important to her coursework but also to her future career.

\section{CONCLUSION}

From Elsie's interview, we see that the weekly feedback had an direct impact on how Elsie communicated with her group members in EMP-Cubed, with her instructors in her other courses, and with potential future employers. Through the tutor feedback, her instructor was able to help Elsie improve in an area of scientific communication (asking questions and voicing opinions even when unsure) that would not be addressed through grades on written assignments or assessments of formal presentations. From the self-feedback, we see Elsie take up this idea of voicing her ideas and confusions, particularly in coding, which she feels uncomfortable with. She was able to build on the idea presented by tutor and continued to work on improving this skill over the semester.

From her interview at the end of the semester, and her selffeedback, we see Elsie making explicit efforts to improve her communication, gaining confidence in her ability to voice her opinion, and seeing the benefits of her efforts in the EMPCubed course, in her other courses, and in her future career. By having the recurrent feedback system, we see that this skill was something Elsie was able to return to and continuously work on over the semester - not just something that she received a grade on once and forgot about. Thus, as a mechanism, we see that this scaffolded weekly feedback can allow students to build on and improve week-to-week in scientific skills that may have otherwise gone unnoticed, such the type of informal scientific communication that occurs in class.

Elsie's interview also offers several directions of future research. In this paper, we have shown how feedback has helped Elsie improve her scientific communication through her reflections in the interview and through her feedback over the semester. We also have in-class video data of Elsie and her group for the first 5 weeks of the course, which we will use to analyze how her in-class behavior changed as a result of this feedback. Elsie also alludes to other skills in her interview that she developed and built on from EMP-Cubed, such as teamwork, delegating tasks, and computation. In our future work, we hope to further investigate and expand on the scientific skills that students are developing in EMP-Cubed, as well as how they are transferring those skills to their other courses and future careers. We also intend to broaden this study beyond a single case study. We recognize that not all students may share Elsie's view of feedback, and we are interested in describing the variety of students' experiences with the feedback system in EMP-Cubed.

\section{ACKNOWLEDGEMENTS}

We would like to thank PERL@MSU for their support of this work, particularly Abhilash Nair and Bridget Humphrey. We also gratefully acknowledge the development team, CREATE4STEM Institute, and the College of Natural Sciences for their support of the EMP-Cubed course development.
[1] J. Kozminski, N. Beverly, D. Deardorff, R. Dietz, M. EblenZayas, R. Hobbs, H. Lewandowski, S. Lindaas, A. Reagan, R. Tagg, J. Williams, and B. Zwickl, American Association of Physics Teachers, 29 (2014).

[2] NGSS Lead States, Next Generation Science Standards: For States, By States (The National Academies Press, Washington, DC, 2013).

[3] S. Adams, "The 10 Skills Employers Most Want In 2015 Graduates," (2014).

[4] P. Heron, L. McNeil, D. Arion, W. Buell, S. J. Gates, S. Giri, E. McCormack, H. Quinn, Q. Williams, and L. Woolf, Phys 21 : Preparing Physics Students for 21st-Century Careers (American Physical Society and American Association of Physics
Teachers, 2016).

[5] "Scientific Abilities - Rubrics,"

[6] E. Etkina, A. Van Heuvelen, S. White-Brahmia, D. T. Brookes, M. Gentile, S. Murthy, D. Rosengrant, and A. Warren, Physical Review Special Topics - Physics Education Research 2, 1 (2006).

[7] P. A. Mills, W. V. Sweeney, S. DeMeo, R. Marino, and S. Clarkson, Journal of Chemical Education 77, 1158 (2000).

[8] B. Jewczyn, S. B. Jones, and E. J. Page, ISEC 2014 4th IEEE Integrated STEM Education Conference (2014), 10.1109/ISECon.2014.6891025.

[9] P. W. Irving, M. J. Obsniuk, and M. D. Caballero, European Journal of Physics 38, 1 (2017). 